\title{
Obliczanie połączeń spawanych węzłów typu N o nakrywających się prętach skratowania, wykonanych z zamkniętych kształtowników prostokątnych
}

\section{Assessment of welded N-type overlap joints of trusses made of hollow sections}

\section{Streszczenie}

Zastosowanie w konstrukcjach stalowych kształtowników o przekrojach zamkniętych cieszy się coraz większą popularnością. Wraz z powstaniem poradników projektowych CIDECT dostępne stały się narzędzia projektowe pozwalające na projektowanie połączeń spawanych węzłów spawanych z rur. Określenie nośności spoin w takich połączeniach jest złożonym problemem, ponieważ wymaga ustalenia długości efektywnych poszczególnych odcinków spoin, ich rozmieszczenia z uwzględnieniem podatności ścianek oraz rozdziału obciążenia na siły składowe działające na indywidualne odcinki spoin. Celem artykułu jest przedstawienie sposobu oceny nośności spoin w węzłach kratownic typu $\mathrm{N}$ z częściowym lub całkowitym nachodzeniem, o pasach wykonanych z rur prostokątnych lub dwuteowników i prętach skratowania wykonanych z rur prostokątnych.

\section{Wstęp}

Przekroje zamknięte wewnątrz puste mają wiele zalet wytrzymałościowo-statecznościowych, eksploatacyjnych, estetycznych, a przy dużej gradacji wymiarów kształtowników i ich grubości są dogodne do oszczędnego projektowania wskutek łatwego doboru potrzebnego do uzyskania konkretnej nośności. Przekroje zamknięte wyparły całkowicie stosowanie kątowników w nowoczesnych rozwiązaniach konstrukcji wiązarów dachowych, przestrzennych kratownic, kładek, wiaduktów i mostów, a także całych budowli (np. stadionów), czy też budynków wielokondygnacyjnych

$$
\begin{aligned}
& \text { Dr inż. Mirosław Broniewicz - Politechnika } \\
& \text { Białostocka. }
\end{aligned}
$$

(w tym konstrukcji zespolonych). Lekkość elementów montażowych, łatwość transportu i ochrony przed korozją oraz przed ogniem korzystnie wpływa na zakres zastosowania od małych do bardzo dużych rozpiętości i wymiarów. Przyczynia się to do obniżenia kosztów inwestowania i użytkowania.

Tradycyjne kształtowanie węzłów, zwłaszcza z rur okrągłych, prowadzi do rozwiązań mało technologicznych, wymagających dużo robocizny warsztatowej, co powoduje, że elementy są zbyt drogie, aby konkurowały pod względem ekonomicznym z elementami z kształtowników walcowanych na gorąco o profilu otwartym. Utrudnienia wykonawcze oraz dość wysoka cena rur, zwłaszcza prostokątnych, spowodowały konieczność opracowania unowocześnionych rozwiązań konstrukcyjnych. 
Dają się one sprowadzić do kilku podstawowych kształtów, odpowiednich zarówno dla rur okrągłych, jak i prostokątnych (lub kwadratowych), dogodnych do półautomatycznego sterowania procesami produkcyjnymi w wytwórni konstrukcji stalowych. Te rozwiązania są zwykle pozbawione dodatkowych blach węzłowych lub żeber, są oszczędne ze względu na zużycie robocizny, lecz wskutek ich podatności wymagają od projektantów uwzględnienia jej skutków. Ze względu na podobieństwo wycinków węzłów do liter są one oznaczane jako węzły typu K, N, KT, T, Y oraz X.

\section{Kształtowanie węzłów typu N}

Węzły $\mathrm{N}$ są odmianą węzłów $\mathrm{K}$, uzyskaną wtedy, kiedy jeden z krzyżulców jest projektowany o nachyleniu względem pasa pod kątem $90^{\circ}$. Projektowanie i obliczanie nośności węzłów $\mathrm{N}$ o wzajemnie nakrywających się prętach skratowania, wykonanych z zamkniętych kształtowników prostokątnych, jest ujęte w PN-EN 1993-1-8 [8] i omówione w publikacjach [4, 5, $7,10]$. Jednak dokumenty normalizujące opracowane przez Międzynarodowy Instytut Spawalnictwa [9], czy też przygotowany na ich podstawie projekt normy ISO [6] tego typu węzła nie ujmują w swoich zaleceniach. Dzieje się tak dlatego, że posługiwanie się wskaźnikiem $\lambda_{o v}$ w przypadku węzła typu $\mathrm{N}$ z nachodzeniem (zakładkę według PN-EN 1993-1-8) jest niesłuszne.

lloraz $\lambda_{o v}$ wyrażony w procentach (wg [2]) jest nieprzydatny do oceny stopnia nakrywania się prętów skratowania w przypadku węzła N. Jeżeli przyjąć pełne umieszczenie słupka na krzyżulcu (rys. 1a), to uzyskuje się w przypadku kształtowników kwadratowych tych samych wymiarów obu prętów: $q=h_{i}$ oraz $p=h_{j} / \sin \Theta_{i}$ co daje:

$$
\lambda_{o v}=q / p \text { stąd } \lambda_{o v}=\sin \Theta_{j}
$$

Rozpatrując, zgodnie z PN-EN 1993-1-8 [8], granice nachylenia krzyżulca o wartości kąta $30^{\circ} \leq \Theta_{j} \leq 60^{\circ}$, uzyskuje się przy:

$$
\begin{aligned}
& \odot_{j}=30^{\circ}, \lambda_{o v}=0,5(50 \%) \\
& \odot_{j}=60^{\circ}, \lambda_{o v}=0,866(86,6 \%)
\end{aligned}
$$

Tymczasem z rysunku 1a wynika pełne umieszczenie słupka na krzyżulcu, czyli powinno być zawsze $\lambda_{o v}=100 \%$.

Wobec tego posługiwanie się wskaźnikiem $\lambda_{o v}$ wskazanym w normie [8], jak i w wielu publikacjach dotyczących tej normy, jest niewłaściwe. W przewodnikach CIDECT (np. [7]) i w podręcznikach (np. [10]) ta nieprawidłowość nie jest odnotowywana, gdyż nigdzie wskazywane wzory obliczeniowe nie odnoszą się do węzłów typu K i N, lecz tylko do typu K.

Zalecenia w PN-EN 1993-1-8 [8], odnoszące się do oceny bezpieczeństwa węzłów typu $\mathrm{N}$ z zakładką (patrz tabl. 7.10) wydają się być co najmniej nieprecyzyjne, a)

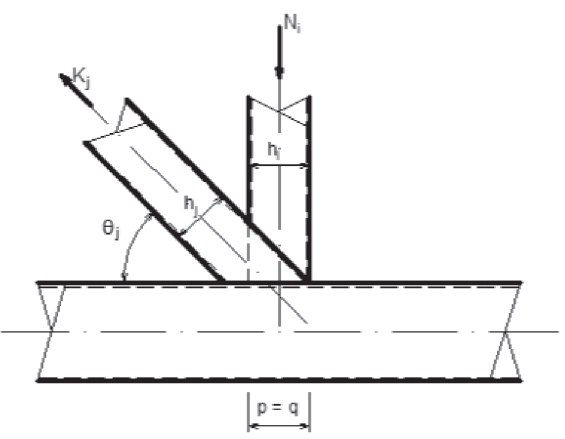

b)

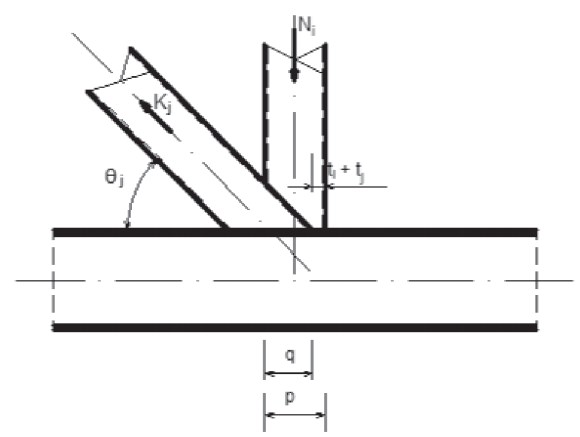

Rys. 1. Węzeł typu N: a) przy pełnym nachodzeniu prętów skratowania, b) przy częściowym nachodzeniu prętów skratowania

Fig. 1 Joint of N-type: a) full overlap of bracing members, b) partial overlap of bracing members

a poprawka wprowadzona do tablicy 7.8 , mówiąca o sprawdzaniu na ścinanie połączenia w płaszczyźnie styku z pasami, jest niemożliwa do poprawnego przeprowadzenia w wielu sytuacjach projektowych. Dzieje się tak dlatego, że oceny $\lambda_{\text {ov, lim }}=50 \%$ lub $\lambda_{\text {ov, lim }}=80 \%$ mogą być wadliwie ustalone, gdy nachylenie krzyżulca mieści się $\mathrm{w}$ granicach $30^{\circ} \leq \Theta_{j} \leq 60^{\circ}$.

Zaniechanie ułożenia spoiny w części połączenia nakrytej przez słupek jest możliwe tylko wówczas, gdy zmieni się wartość $\lambda_{\text {ov,lim }}$ na mniejszą niż $50 \%$ lub $80 \%$ (i to niekiedy znacznie).

Węzeł typu $\mathrm{N}$ powinien być zawsze projektowany w taki sposób, żeby ściskany słupek częściowo lub całkowicie nakrywał rozciągany krzyżulec, ponieważ takie rozwiązanie jest prostsze do wykonania. Zakres stosowania tych węzłów jest taki sam, jak węzłów typu $\mathrm{K}$ (patrz [2]). Aby spoina poprzeczna łącząca słupek od strony pasa nie pokrywała się ze spoiną poprzeczną, łączącą tam również krzyżulec z pasem, częściowe lub całkowite nakrywanie powinno być tak zaprojektowane, żeby spoiny były układane do siebie równolegle co najmniej w odstępie $t_{i}+t_{j}$ (rys. 1b).

Ze względu na raczej nieduże wartości nachodzenia $q$, wynikające $z$ wysokości przekroju słupka, korzystanie z normowego zezwolenia, aby spoina pachwinowa w miejscu zakrytym nie była wykonana, jest niewskazane, chyba że siły w prętach skratowania są niedużej wartości w stosunku do ich nośności. 


\section{Ustalanie długości współpracujących spoin i ich obciążenia}

Ustalenie obciążenia działającego w poszczególnych odcinkach spoin pachwinowych wymaga najpierw rozdzielenia sił zbiegających się w węźle z prętów skratowania na ich składowe równoległe lub prostopadłe do płaszczyzn styku z pasem i w bezpośrednim styku między słupkiem i krzyżulcem. Postępuje się podobnie, jak przedstawiono $\mathrm{w}$ [2].

Siła składowa krzyżulca równoległa do osi pasa jest całkowicie przenoszona przez połączenie w płaszczyźnie styku krzyżulca (i słupka) z tym prętem. Natomiast składowa siły krzyżulca prostopadła do osi pasa jest przenoszona częściowo z jednego pręta skratowania na drugi bezpośrednio w ich styku, a częściowo przez połączenie w ich stykach z pasem. Aby taki podział nie powodował nadmiernego przeciążenia spoin czołowych, bezpośrednio między prętami skratowania ustala się konstrukcyjny warunek, że nakrywanie krzyżulca przez słupek powinno wynosić co najmniej $q=0,25 h_{i}$ (gdzie $h_{i}$ jest wysokością przekroju słupka). Wzorując się na sposobie podziału, zaproponowanym w [2], można zapisać wartość siły przenoszonej bezpośrednio przez spoiny między krzyżulcem i słupkiem:

$$
\begin{array}{lll}
\Delta K_{i}=\alpha_{N} K_{i} \sin \bigodot_{i} & \text { gdy } & 0,25 h_{i} \leq q \approx h_{i} \\
\Delta K_{i}=K_{i} \sin \odot_{i} & \text { gdy } & q \geq h_{i}
\end{array}
$$

Pozostała część składowej siły prostopadłej do pasa wynosi:

$$
\begin{aligned}
& \Delta\left(1-\alpha_{N}\right) K_{i} \sin \Theta_{i} \quad \text { ze słupka, gdy } 0,25 h_{i} \leq q \approx h_{i} \\
& \text { red } \Delta K_{j}=K_{j} \sin \Theta_{j}-\alpha_{N} K_{i} \sin \Theta_{i} \text {, gdy } 0,25 h_{i} \leq q \approx h_{i} \text { (6) } \\
& \text { red } \Delta K_{j}=K_{j} \sin \Theta_{j}-K_{i} \sin \Theta_{i}, \quad \text { gdy } q>h_{i}
\end{aligned}
$$

red $\Delta K_{j}=0$, gdy $q>h_{i}$, jeżeli do węzła nie jest przyłożone obciążenie zewnętrzne kratownicy, przy czym: $\alpha_{N}=q / h_{i}$

Tak ustalone obciążenia składowe działają w płaszczyznach styków między prętami skratowania i w płaszczyźnie ich styku z pasem. W tym drugim przypadku wstępują dwie sytuacje projektowe zależne od tego, jaki rodzaj kształtownika zastosowano na pas, a mianowicie w przypadku:

I - zamkniętego kształtownika o przekroju prostokątnym - rysunek 2,

II - dwuteownika europejskiego lub szerokostopowego - rysunek 3.

Na tych rysunkach pokazano w ich częściach:

a) rozwiązanie konstrukcyjne węzła i siły w prętach skratowania,

b) układ połączenia na spoiny pachwinowe, gdy $q<h_{p}$ c) układ połączenia na spoiny pachwinowe, gdy $q=h_{i}$.

Ustalenie długości współpracujących odcinków spoin pachwinowych rozpatruje się w oparciu o sytuację projektową I (pas z kształtowników zamkniętych) (rys. 4): a)

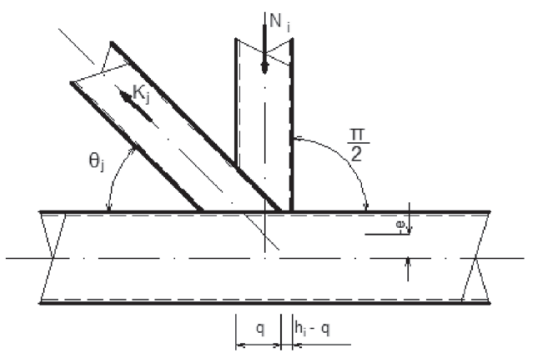

b)

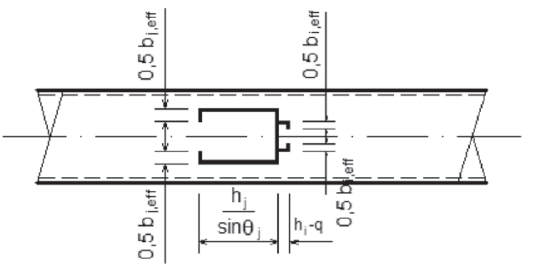

c)

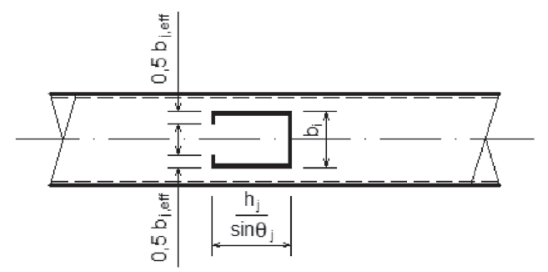

Rys. 2. Układ spoin pachwinowych węzła typu $\mathrm{N}$ z nachodzeniem, gdy pas wykonano z kształtownika prostokątnego: a) widok węzła, b) kład spoin przy częściowym przykryciu przez słupek, c) kład spoin przy całkowitym przykryciu przez słupek

Fig. 2. Layout of fillet welds of overlap N-type joint with the chord made of hollow section: a) joint view, b) welds in joint with partial overlap, c) welds in joint with full overlap

a)

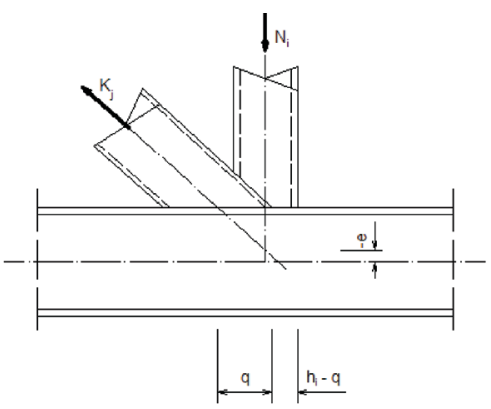

b)

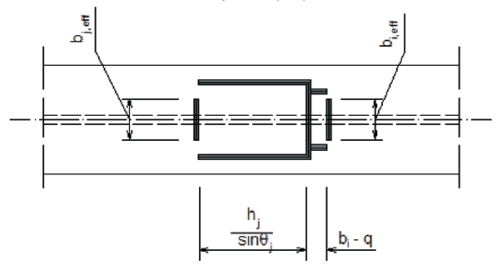

c)

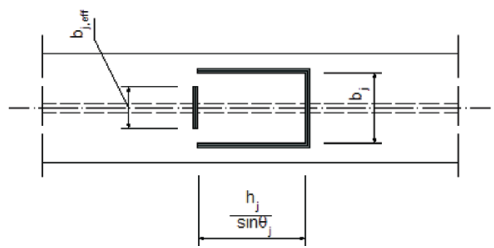

Rys. 3. Układ spoin pachwinowych węzła typu $\mathrm{N} z$ nachodzeniem, gdy pas wykonano z dwuteownika: a) widok węzła, b) kład spoin przy częściowym przykryciu przez słupek, c) kład spoin przy całkowitym przykryciu przez słupek

Fig. 3 Layout of fillet welds of overlap N-type joint with the chord made of H-section: a) joint view, b)welds in joint with partial overlap, c) welds in joint with full overlap 
$l_{1}=h_{j} / \sin \bigodot_{j}$

$l_{2}=b_{j, e f f}=\frac{10}{b_{0} / t_{0}} \cdot \frac{t_{0} f_{v 0}}{t_{j} f_{y j}} b_{j}$

lecz: $b_{j, e f f} \leq b_{j}, \quad b_{j, r e d}=b_{j}-2 a_{w}$

$l_{3}=h_{i, \text { red }}=\left(1-\alpha_{N}\right) h_{i} / \sin \odot$

$l_{4}=b_{i, e f f}=\frac{10}{b_{0} / t_{0}} \cdot \frac{t_{0} f_{y 0}}{t_{i} f_{y i}} b_{i}$

lecz: $b_{i, e f f} \leq b_{i}$.

Natomiast w sytuacji projektowej II (pas z dwuteownika): rys. $5: l_{l}, l_{3}, b_{j, \text { red }}$ jak uprzednio,

$$
\begin{aligned}
& l_{2}=p_{j, e f f}=t_{w}+2 r+7 t_{f} f_{y 0} / f_{y j} \leq b_{j}, \\
& l_{4}=p_{i, e f f}=t_{w}+2 r+7 t_{f} f_{y 0} / f_{y i} \leq b_{i} \text {, }
\end{aligned}
$$

przy czym

$\odot_{i}, \odot_{j}-$ jak na rysunku 2 ,

$b_{i}, b_{j}$ - szerokość zamkniętych kształtowników prostokątnych zastosowanych na pręty skratowania,

$t_{i}, t_{j}, t_{0}$ - grubość prętów skratowania lub pasa z kształtownika zamkniętego,

$t_{p} t_{w}-$ grubość stopki lub środnika dwuteownika,

$r$ - promień zaokrąglenia między środnikiem a stopką dwuteownika,

$f_{y i} f_{y j^{\prime}} f_{y 0}$ - granice plastyczności stali zastosowanej na pręty skratowania lub pas,

$a_{w}$ - grubość spoiny.

Gdy $0,25 h_{i} \leq q \approx h$, wówczas w styku prętów skratowania z pasem składowe równoległe obciążają kład spoin według rysunku $4 a$ lub rysunku 5a. Siły przypadające na poszczególne odcinki wynoszą:

a)

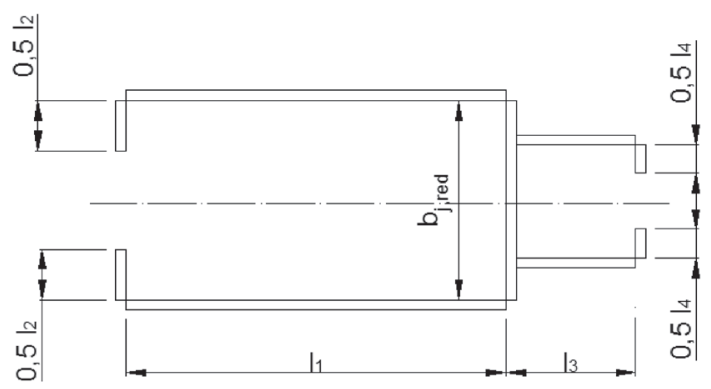

b)

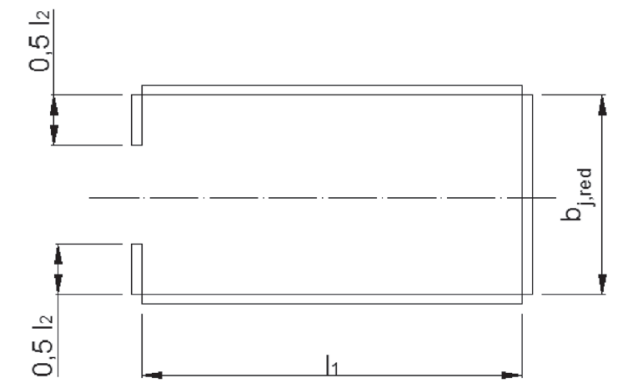

Rys. 4. Przekroje obliczeniowe spoin, gdy pas wykonano z zamkniętego kształtownika prostokątnego przy ułożeniu wszystkich spoin w przypadku: a) $q<h_{i}$, b) $q=h_{i}$

Fig. 4. Design cross-sections of welds with the chord made of rectangular hollow section in case of all welds arranged: a) $q<h_{i}$, b) $q=h$

$$
\left.\begin{array}{l}
P_{1}{ }^{\prime}=K_{j} \cos \Theta_{j} l_{1} / \Sigma l ; P_{2}{ }^{\prime}=K_{j} \cos \Theta_{j} l_{2} / \Sigma l \\
P_{b, \text { red }}=K_{j} \cos \Theta_{j} b_{j, \text { red }} / \Sigma l \\
P_{3}=K_{j} \cos \Theta_{j} l_{3} / \Sigma l ; P_{4}{ }^{\prime}=K_{j} \cos \Theta_{j} l_{4} / \Sigma l
\end{array}\right\}
$$

gdzie: $\Sigma l=2 l_{1}+l_{2}+2 l_{3}+l_{4}+b_{j, r e d}$

Gdy $q=h$, wówczas całe składowe równoległe do pasa są przekazywane na kład według rysunku $4 \mathrm{~b}$ lub rysunku $5 b$. Siły przypadające na poszczególne odcinki wyznacza się z równania (8), przy czym $P_{3}{ }^{\prime}=0$ oraz $P_{4}^{\prime}=0$.

Siły prostopadłe do pasa obciążają kład spoin w przypadku sytuacji projektowej I według rysunku 4a. Uzyskuje się wówczas:

$$
\begin{aligned}
& P_{1}{ }^{\prime \prime}=\operatorname{red} \Delta K_{j} l_{1} /\left(2 l_{1}+l_{2}+b_{j, \text { red }}\right) ; P_{2}{ }^{\prime \prime}=\operatorname{red} \Delta K_{j} l_{2} /\left(2 l_{l}+l_{2}+b_{j, \text { red }}\right) ; \\
& P_{b}{ }^{\prime \prime}=\operatorname{red} \Delta K_{j} b_{j, \text { red }} /\left(2 l_{1}+l_{2}+b_{j, \text { red }}\right) \\
& P_{3}{ }^{\prime \prime}=\Delta\left(1-\alpha_{\mathrm{N}}\right) K_{i} l_{3} /\left(2 l_{3}+l_{4}\right) ; P_{4}{ }^{\prime \prime}=\Delta\left(1-\alpha_{\mathrm{N}}\right) K_{i} l_{4} /\left(2 l_{3}+l_{4}\right) ;
\end{aligned}
$$

Z kolei w sytuacji projektowej II jest (rys. 5a): $P_{1} "=0$ oraz $P_{2},, P_{3}, P_{4}, P_{b}$ "według równań (10).

Składowe sił obciążające połączenie bezpośrednie między prętami skratowania, jak też długości współpracujących odcinków spoin ustala się w sposób przedstawiony w [2], pamiętając, że $\odot_{i}=\pi / 2$.

a)

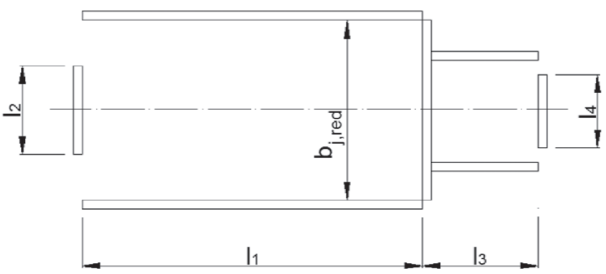

b)

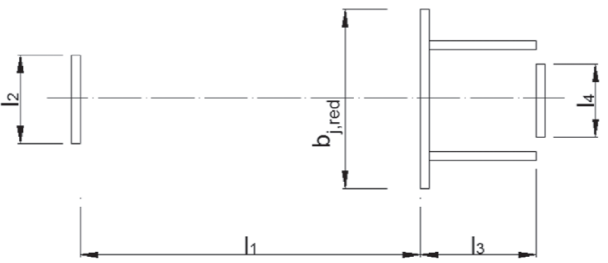

Rys. 5. Przekroje obliczeniowe spoin, gdy pas wykonano $z$ dwuteownika przy ułożeniu wszystkich spoin w przypadku: a) $q<h_{i}$, b) $q=h_{\text {i }}$ Fig. 5. Design cross-sections of welds with the chord made of $\mathrm{H}$ section in case of all welds arranged: a) $q<h_{i}$, b) $q=h_{i}$

\section{Wyznaczanie składowych naprężeń i ocena nośności złączy}

Składowe naprężeń: $\sigma_{\perp}{ }^{\prime}, \tau_{\perp}{ }^{\prime}$ i $\tau_{\|}$, jak również $\sigma_{\perp}{ }^{\prime}$, $\tau_{\perp}$ ”' i $\tau_{\Perp}$ ", w zależności od naprężeń $\sigma$ ' i $\sigma$ ' wyznacza się w sposób przedstawiony w [2], korzystając z zamieszczonych tam rysunków. Ze względu na to, że 
w tej publikacji dostosowano zwroty sił w krzyżulcu i słupku do najczęstszych sytuacji obliczeniowych, podczas wyznaczania wartości tych składowych naprężeń należy zmienić znaki odpowiednio do rozpatrywanej sytuacji. Tu łatwo zdarzają się pomyłki. Aby ułatwić pracę projektantowi, rozpatrzono zagadnienia ponownie, wtedy, kiedy krzyżulec jest rozciągany, a słupek ściskany.

Naprężenia w spoinach od obciążeń równoległych do pasa wynoszą:

a) Na odcinkach podłużnych dla spoin ułożonych:

- przy ściankach krzyżulca:

$\sigma^{\prime}=0 ; \sigma_{\perp}{ }^{\prime}=\tau_{\perp}{ }^{\prime}=0 ; \tau_{\|}{ }^{\prime}=P_{1}{ }^{\prime} / a_{w} l$

- przy ściankach słupka:

$\sigma^{\prime}=0 ; \sigma_{\perp}{ }^{\prime}=\tau_{\perp}{ }^{\prime}=0 ; \tau_{\text {॥I }}{ }^{\prime}=P_{3}{ }^{\prime} / a_{w} l_{3}$

b) Na odcinku poprzecznym nie w pełni współpracującym krzyżulca:

$$
\sigma^{\prime}=P_{2}{ }^{\prime} / a_{w} l_{2} ; \sigma_{\perp}{ }^{\prime}=-\sigma^{\prime} \sin \left(\odot_{j} / 2\right) ; \tau_{\perp}^{\prime}=-\sigma^{\prime} \cos \left(\odot_{j} / 2\right) ; \tau_{\|}{ }^{\prime}=0
$$

c) Na odcinku poprzecznym w pełni współpracującym krzyżulca:

$$
\sigma^{\prime}=P_{b}{ }^{\prime} / a_{w} b_{j, r e d} j^{\prime} \sigma_{\perp}^{\prime}=-\sigma^{\prime} \cos \left(\bigodot_{j} / 2\right) ; \tau_{\perp}{ }^{\prime}=-\sigma{ }^{\prime} \sin \left(\odot_{j} / 2\right) ; \tau_{\|}{ }^{\prime}=0
$$

d) Na odcinku poprzecznym nie w pełni współpracującym słupka:

$$
\sigma^{\prime}=P_{4}^{\prime} / a_{w} l_{4} ; \sigma_{\perp}^{\prime}=-\sigma_{-}^{\prime} \sqrt{2} / 2 ; \tau_{\perp}^{\prime}=-\sigma_{-}^{\prime} \sqrt{ } 2 / 2 ; \tau_{\|}{ }^{\prime}=0
$$

Naprężenia w spoinach od obciążeń prostopadłych do pasa wynoszą:

a) Na odcinkach podłużnych spoin ułożonych:

- przy ściankach krzyżulca:

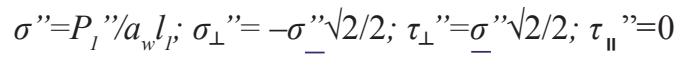

- przy ściankach słupka:

$$
\sigma "=P_{3}{ }^{\prime \prime} / a_{w} l_{3} ; \sigma_{\perp} "=-\sigma ” \sqrt{ } 2 / 2 ; \tau_{\perp} "=-\sigma ” \sqrt{ } 2 / 2 ; \tau_{\Perp}{ }^{\prime \prime}=0
$$

b) Na odcinku poprzecznym nie w pełni współpracującym krzyżulca:

$$
\sigma "=P_{2}{ }^{\prime \prime} / a_{w} l_{2} ; \sigma_{\perp}{ }^{\prime \prime}=\sigma " \cos \left(\Theta_{j} / 2\right) ; \tau_{\perp}{ }^{\prime \prime}=-\sigma " \sin \left(\odot_{j} / 2\right) ; \tau_{\|}{ }^{\prime \prime}=0
$$

c) $\mathrm{Na}$ odcinku poprzecznym w pełni współpracującym krzyżulca:

$$
\sigma "=P_{b}{ }^{\prime \prime} / a_{w} b_{j, r e d} ; \sigma_{\perp} "=-\sigma " \cos \left(\odot_{j} / 2\right) ; \tau_{\perp}{ }^{\prime \prime}=\sigma " \sin \left(\odot_{j} / 2\right) ; \tau_{\|}{ }^{\prime \prime}=0
$$

d) Na odcinku poprzecznym nie w pełni współpracującym słupka:

$$
\sigma "=P_{4}{ }^{\prime \prime} / a_{w} l_{4} ; \sigma_{\perp}{ }^{\prime}=\sigma " \sqrt{ } 2 / 2 ; \tau_{\perp}{ }^{\prime \prime}=-\sigma{ }^{\prime \prime} \sqrt{ } 2 / 2 ; \tau_{\|}{ }^{\prime \prime}=0
$$

Składowe naprężeń na poszczególnych odcinkach należy sumować, biorąc wartości-określone przy działaniu sił w krzyżulcach po ich przetworzeniu na składowe równoległe lub prostopadłe do osi pasa, czy też równoległe lub prostopadłe do osi krzyżulca nakrywanego (pamiętając o ich znakach):

$$
\begin{aligned}
& \tau_{\|}=\tau_{\|}{ }^{\prime}+\tau_{\|}{ }^{\prime \prime} \\
& \sigma_{\perp}=\sigma_{\perp}{ }^{\prime}+\sigma_{\perp}{ }^{\prime}, \\
& \tau_{\perp}=\tau_{\perp}{ }^{\prime}+\tau_{\perp}{ }^{\prime},
\end{aligned}
$$

Mając wyznaczone składowe sumaryczne, przystępuje się do oceny bezpieczeństwa w połączeniu spoin poprzecznych i podłużnych (w pełni lub częściowo współpracujących), stosując wzory normowe:

$$
\left[\sigma_{\perp}^{2}+3\left(\tau_{\perp}^{2}+\tau_{\|}^{2}\right)\right]^{0,5} \leq f_{u} /\left(\beta_{w} \gamma_{M 2}\right)
$$

oraz

$$
\sigma_{\perp} \leq 0,9 f_{u} / \gamma_{M 2}
$$

gdzie: $\beta_{w}$ - współczynnik korelacji spoin pachwinowych, $f_{u}$ - odpowiednia wytrzymałość na rozciąganie stali, $\gamma_{M 2}=1,25$ - współczynnik bezpieczeństwa.

\section{Podsumowanie}

Węzły kratownic wykonanych z kształtowników o przekrojach zamkniętych są węzłami podatnymi, głównie z powodu stosowanej technologii ich wykonania, tzn. bezpośredniego spawania elementów skratowania do stosunkowo cienkiej ścianki czołowej pasa. Podstawy obliczania nośności spoin w tego typu połączeniach przedstawione w normie europejskiej oraz innych dokumentach normalizacyjnych zawierają tylko bardzo ogólne stwierdzenia, nie podając żadnych szczegółowych procedur wymiarowania, które projektanci mogliby wykorzystać w swojej pracy. Ponadto dotyczą one tylko węzłów typu $\mathrm{T}, \mathrm{X}, \mathrm{K}$ oraz $\mathrm{N}$ kształtowanych z odstępem między prętami skratowania, natomiast brak jest informacji dotyczących sprawdzania nośności spoin w węzłach typu K i N wykonywanych z częściowym lub całkowitym nachodzeniem prętów skratowania na siebie.

Przedstawiono metodę sprawdzenia nośności spoin w węzłach typu $\mathrm{N}$ kratownic o pasach wykonanych z rur prostokątnych lub dwuteowników i prętach skratowania wykonanych z rur prostokątnych, o prętach skratowania częściowo lub całkowicie nachodzących na siebie w węźle. Metoda ta obejmuje określenie naprężeń w spoinach w różnych stanach obciążenia w zależności od ich długości efektywnych i porównanie ich z wartościami dopuszczalnymi. 


\section{Profesor Władysław Włosiński Doktor Honoris Causa Politechniki Świętokrzyskiej}

W dniu 12 czerwca 2013 r. w Głównej Auli Wykładowej Politechniki Świętokrzyskiej w Kielcach został nadany Profesorowi dr hab. inż. Władysławowi Wosińskiemu tytuł Doktora Honoris Causa Politechniki Świętokrzyskiej w Kielcach.

Nadanie tego tytułu stanowi wyraz uznania dla Prof. Władysława Włosińskiego jako uczonego i uhonorowania wieloletniej współpracy z Uczelnią.

Profesor Władysław Włosiński jest specjalistą w dziedzinie technologii materiałowych, znawcą najnowocześniejszych materiałów, twórcą zaawansowanych metod różnych niemetali z metalami. Wyniki badań Profesora publikowane były na całym świecie w formie artykułów i książek stanowiąc bardzo bogaty dorobek publikacyjny. Był i nadal jest opiekunem naukowym wielu adeptów nauki jako promotor i recenzent ich prac. Jednocześnie Profesor pełnił szereg odpowiedzialnych funkcji: m.in. członka Prezydium Polskiej Akademii Nauk i Przewodniczący Wydziału IV Nauk Technicznych Polskiej Akademii Nauk.

Profesor Władysław Włosiński jest również osobą niezwykle zasłużoną dla kieleckiego ośrodka naukowego w tym jest współtwórcą Centrum Laserowych Technologii Metali (dawniej Centrum Badawczego Technologii Laserów) w Kielcach, w którym do dnia dzisiejszego jest członkiem Rady Programowej. Profesor swoją działalnością organizacyjną i naukową wywarł pozytywne piętno w kieleckim środowisku naukowym współtworząc atmosferę akademickości i inspirując badania naukowe ukierunkowane na nowe technologie laserowej obróbki metali i tworzyw ze szczególnym uwzględnieniem laserowego kształtowania metali.

Wybitnemu Profesorowi, Panu Profesorowi Władysławowi Włosiskiem, pragnę złożyć w imieniu swoim i zespołu redakcyjnego miesięcznika naukowo-technicznego Przegląd Spawalnictwa najserdeczniejsze życzenia zdrowia i dotychczasowej energii oraz nowych pomysłów w kierowaniu pracami naukowymi.

Prof. dr hab. inż. Jerzy Nowacki Redaktor Naczelny

Literatura (c.d. ze str. 38)

[1] Bródka J., Broniewicz M.: Obliczanie połączeń spawanych węzłów kratownic z rur prostokątnych. - Konstrukcje Stalowe. 2002 nr 4, s. 29-34.

[2] Bródka J., Broniewicz M.: Calculation of welding trusses overlap joints, Archives of Civil Engineering. Committee for Civil Engineering, Polish Academy of Sciences: 2013. 24 p.

[3] Bródka J., Broniewicz M.: Ocena nośności połączeń spawanych z rur według EN 1993-1-8: Konstrukcje Stalowe, 2007, nr 1, s. 32-38.

[4] Bródka J., Broniewicz M.: Konstrukcje stalowe z rur. Arkady. Warszawa 2001

[5] Bródka J., Kozłowski A., Ligocki I., Łaguna J., Ślęczka L.: Projektowanie i obliczanie połączeń i węzłów konstrukcji stalowych. Tom 1. PWT. Rzeszów 2009.
[6] BS ISO 14346 Welding - Static design procedure for hollow section joints. Draft 2011.

[7] Packer J. A., Wardenier J., Zhao X.-L., van der Vegte G. $J .:$ Design guide for rectangular hollow section (RHS) joints under predominantly static loading. Second Edition. LSS Verlag. CIDECT 2009.

[8] PN-EN 1993-1-8:2006 Eurokod 3: Projektowanie konstrukcji stalowych - Część 1-8: Projektowanie węzłów.

[9] Static procedure for welded hollow section joints. Recommendations. 3rd Edition. International Institute of Welding. Commission XV. IIW Doc. XV-1329-09.

[10] Wardenier J., Packer J. A., Zhao X.-L., van der Vegte G. J. Hollow section in structural applications. Bouwen met staal. Zoeteman 2010. 